\title{
Medical Image of the Week: Killian-Jamieson Diverticulum
}

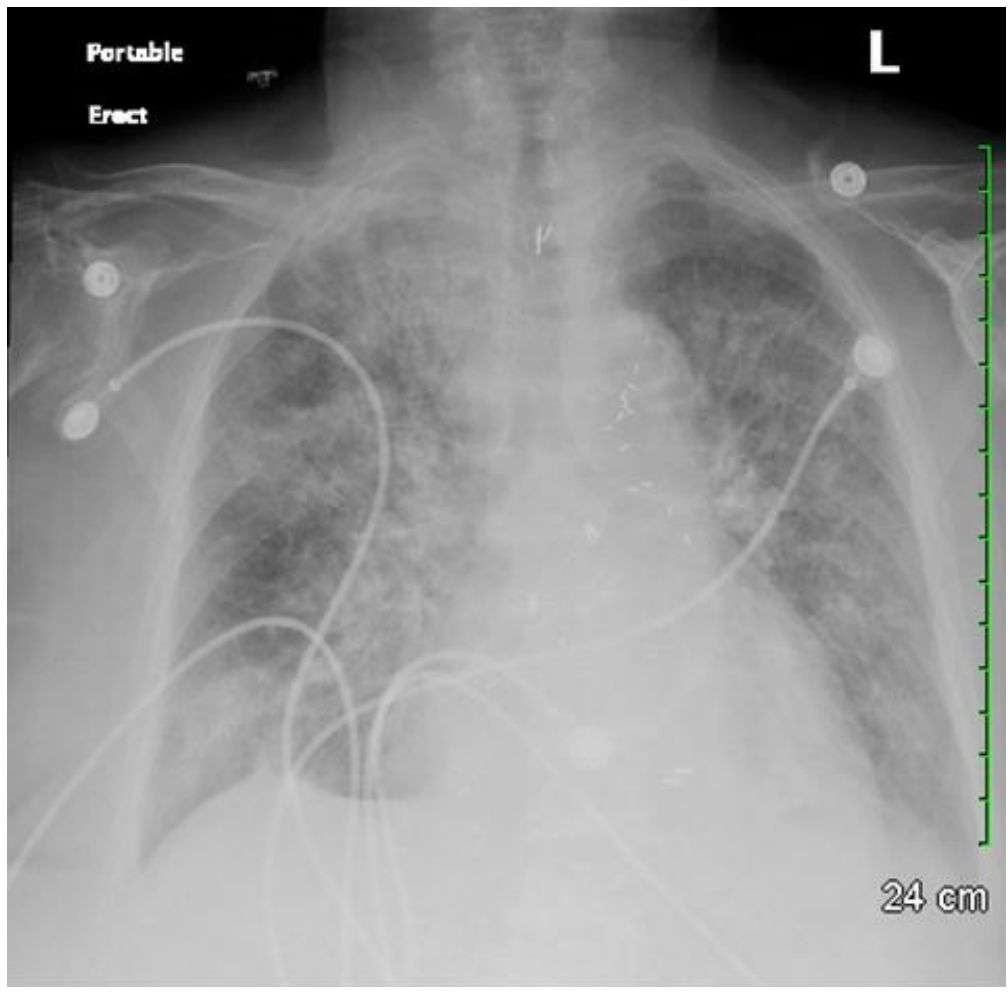

Figure 1. Chest $x$-ray showing worsening consolidation in both lungs.
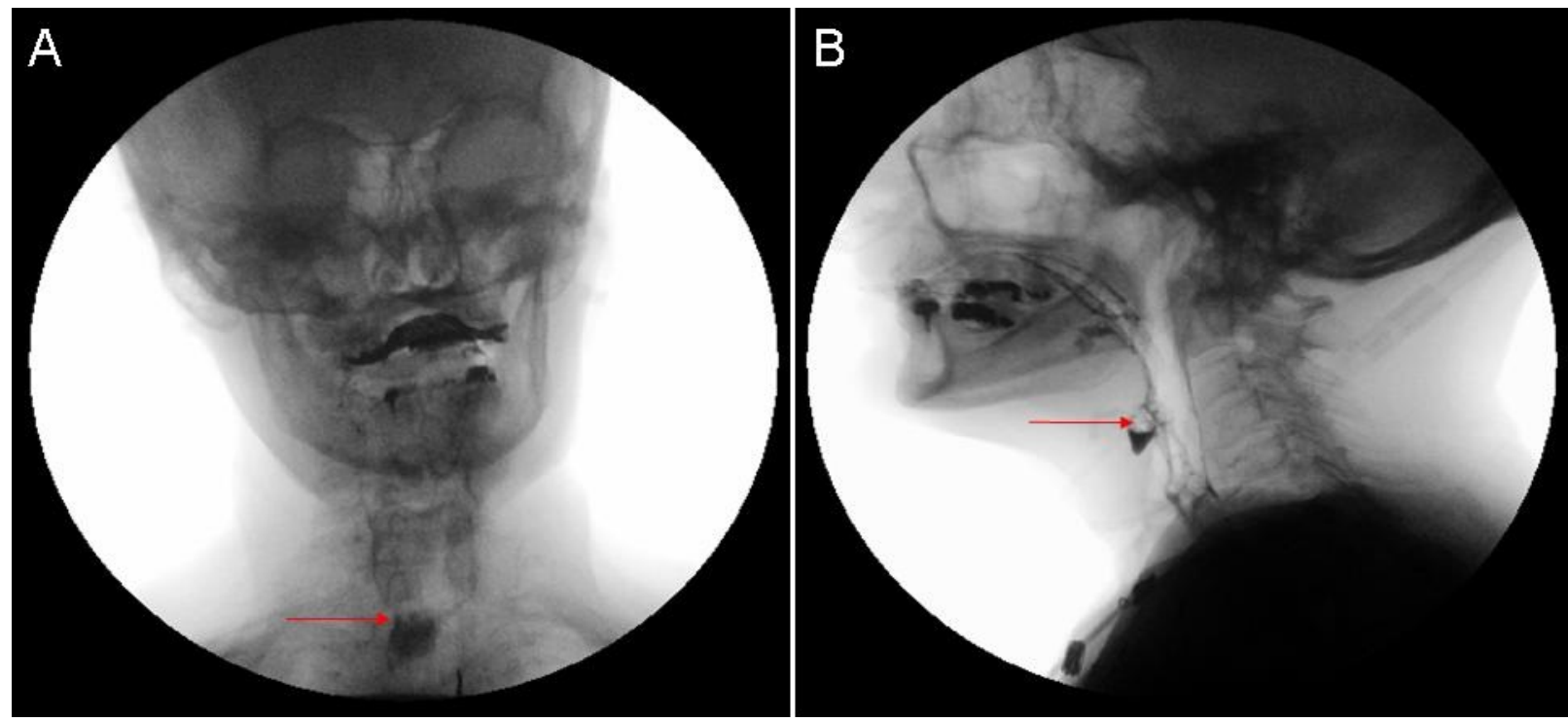

Figure 2. Anterior (panel A) and lateral (panel B) fluoroscopic images showing retained contrast material in the anterior esophageal diverticulum in the hypopharynx. 
An 89 year old female nursing home resident with a past medical history of hypertension and coronary artery disease was admitted with generalized weakness and vomiting for two days. Chest x-ray revealed consolidation in the left lung suggestive of pneumonia and she was started on broad spectrum antibiotics. Due to worsening consolidation in both lung fields (Figure 1) a video swallow was done for possible aspiration, which revealed contrast retained within the proximal esophagus within a diverticula in the anterior aspect (Figure 2). After excision of the diverticulum her pneumonia resolved and she was discharged back to the nursing home.

Killian-Jamieson diverticulum is a mucosal protrusion through a muscular gap in the anterolateral wall of the cervical esophagus; inferior to the cricopharyngeus and lateral to the longitudinal muscle of the esophagus just below its insertion on the posterior lamina of cricoid cartilage (gap also known as Killian-Jamieson space). This differentiates it from the Zenker's diverticulum which arises from the muscular gap in the posterior portion of cricopharyngeus muscle (also known as Killian's dehiscence). Killian-Jamieson diverticulum causes more non-specific symptoms than Zenker's diverticulum. Because these diverticula occur in close proximity to the recurrent laryngeal nerve, it should be carefully preserved during surgical resection.

Chandramohan Meenakshisundaram, MD and Nanditha Malakkla, MD Medical Education

Saint Francis Hospital

Evanston, IL

\section{References}

1. Kim DC, Hwang JJ, Lee WS, Lee SA, Kim YH, Chee HK. Surgical treatment of killian-jamieson diverticulum. Korean J Thorac Cardiovasc Surg. 2012;45(4):272-4. [CrossRef] [PubMed]

2. Siddiq MA, Sood S, Strachan D. Pharyngeal pouch (Zenker's diverticulum). Postgrad Med J. 2001;77:506-11. [CrossRef] [PubMed]

3. Brant WE, Helms CA. Fundamentals of Diagnostic Radiology. Lippincott Williams \& Wilkins. (2007) ISBN:0781765188 